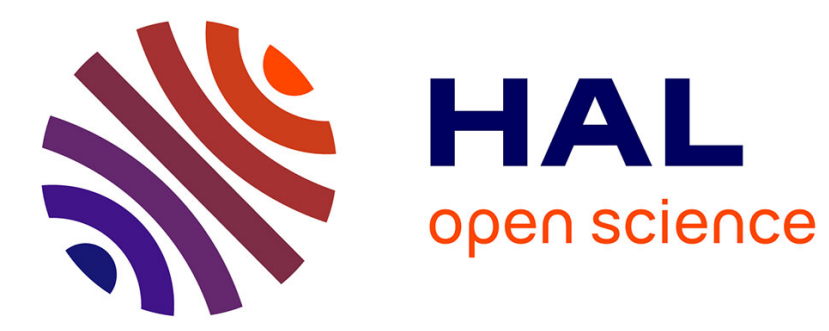

\title{
Genetic polymorphism of the C-reactive protein (CRP) gene and a deep infection focus determine maximal serum CRP level in bacteremia
}

T. Mölkänen, A. Rostila, E. Ruotsalainen, M. Alanne, M. Perola, A. Järvinen

\section{- To cite this version:}

T. Mölkänen, A. Rostila, E. Ruotsalainen, M. Alanne, M. Perola, et al.. Genetic polymorphism of the C-reactive protein (CRP) gene and a deep infection focus determine maximal serum CRP level in bacteremia. European Journal of Clinical Microbiology and Infectious Diseases, 2010, 29 (9), pp.11311137. 10.1007/s10096-010-0978-z . hal-00600768

\section{HAL Id: hal-00600768 https://hal.science/hal-00600768}

Submitted on 16 Jun 2011

HAL is a multi-disciplinary open access archive for the deposit and dissemination of scientific research documents, whether they are published or not. The documents may come from teaching and research institutions in France or abroad, or from public or private research centers.
L'archive ouverte pluridisciplinaire HAL, est destinée au dépôt et à la diffusion de documents scientifiques de niveau recherche, publiés ou non, émanant des établissements d'enseignement et de recherche français ou étrangers, des laboratoires publics ou privés. 
Diseases

Editorial Manager(tm) for European Journal of Clinical Microbiology \& Infectious

Manuscript Draft

Manuscript Number: EJCMID-D-10-00008R1

Title: Genetic polymorphism of C-reactive protein (CRP) gene and a deep infection focus determine maximal serum CRP level in Staphylococcus aureus bacteremia

Article Type: Article

Keywords: Staphylococcus aureus bacteremia; C-reactive protein; single nucleotide polymorphisms

Corresponding Author: Dr. Tomi Juhani Mölkänen, M.D.

Corresponding Author's Institution: Helsinki University Central Hospital

First Author: Tomi Mölkänen, M.D.

Order of Authors: Tomi Mölkänen, M.D.; Annina Rostila, M.Sc. ; Eeva Ruotsalainen, M.D., Ph.D.; Mervi Alanne, Ph.D.; Markus Perola, M.D., Ph.D; Asko Järvinen, M.D., Ph.D

Abstract: CRP is widely used in early detection of sepsis or organ dysfunction. Several SNPs in the CRP gene are shown to be associated with variability of basal CRP. To clarify the effect of SNPs to CRP in systemic infections, we compared genetic and clinical data on patients with Staphylococcus aureus bacteremia(SAB). Six SNPs in the CRP gene (rs2794521, rs30912449, rs1800947, rs1130864, rs1205 and rs3093075) were genotyped in 145 patients and analyzed for associations with CRP and clinical outcomes. We found minor A-allele of triallelic SNP rs30912449 (C>T>A) and presence of a deep infection focus independently associate to the higher maximal CRP during the first week of SAB. Median of the maximal CRP in patients who had the A-minor allele was $282 \mathrm{mg} / \mathrm{L}$ [IQR, $169 \mathrm{mg} / \mathrm{L}$ ) but only $179 \mathrm{mg} / \mathrm{L}(\mathrm{IQR}, 148 \mathrm{mg} / \mathrm{L})$ in patients without this allele $(\mathrm{P}=0.004)$ and CRP in patients who had deep infection focus was higher $208 \mathrm{mg} / \mathrm{L}$ (IQR, 147mg/L) than in other patients $114 \mathrm{mg} / \mathrm{L}$ (IQR, 121 $\mathrm{mg} / \mathrm{l})(\mathrm{P}<0.0001)$. Mortality, degree of leucocytosis, time to defervescence or number of deep infections were not affected by SNPs. The maximal CRP in SAB was determined by variation in the CRP gene and by presence of deep infection focus.

Response to Reviewers: Reviewer \#1

Please find enclosed our revised manuscript entitled "Genetic polymorphism of C-reactive protein (CRP) gene and a deep infection focus determine maximal serum CRP level in Staphylococcus aureus bacteremia". We are grateful for the valuable comments of the referees which have all lead to changes in manuscript. One of the suggestions of referee 1 led us to reanalyse one part of the statistics which has resulted in a modification of title of manuscript. We sincerely consider this reanalysis to have improved the manuscript and its importance for the scientific community. Please find enclosed reviewer questions and author answers after each guestion.

Reviewer \#1:

1. Page 4 , line 21 . Were the 430 patients unique or if a patient returned with a second episode of S. aureus bacteremia (SAB), were they included a second time? Please clarify this in the text. 
Answer to question 1.)Each patient was included into the study only once. This has been added in the methods in the paragraph "patient population" on Page 4 lines 20-21.

2. page 7, lines 19-26; Table 2; and online resource supplementary table. I am concerned by the number of statistical tests that were performed - I count 33 statistical tests in the supplementary table and table 2 . By chance alone, one would expect that $1 / 20$ might be found to be significant.

Is it possible to adjust the finding for the number of tests performed? If not, or if this adjustment produces a p-value of $>0.05$ for the observed significant associations, this should be noted as a limitation of the study.

Answer to question 2.) Multiple comparisons has now been analysed by False-discovery rate (FDR) estimation. It has been included into the statistics section of methods page 6 lines 19-20. Results from FDR analysis have been shown in tables 2 and 4.

3. Table 2 . Why do the data for this Table only include 116 patients while the remainder of the genotypic analyses include 133 - 144 patients (see supplementary table)?

Answer to question 3.) Table 2 includes only 116 patients because genotyping in laboratory of SNP rs3091244 was successful only in 116 patients. This specific triallelic SNP turned out to be technically much more challenging to sequence compared to all other biallelic SNPs studied.

4. Is there any information as to the antimicrobial or surgical treatment provided patients (surgical intervention or even the placement of a central venous catheter could certainly increase the CRP)? The duration of symptoms prior to the onset of therapy? These are important covariates to consider in assessing CRP levels. If information is not available, these may be important limitations of the study.

Answer to question 4.) Surgical procedures during the first week have been analysed as suggested by the referee and were found not to affect the maximal CRP level. However, we analysed also the effect of presence of a deep infection focus on the maximal CRP level and found this association highly significant. Patients with deep infection foci have been added into table 3 and this information into results on Page 7 lines 13-18 and into Table 4. This finding has been further discussed in a new written part of discussion on Page 4, in paragraph two. We considered this finding of so high importance that it has resulted into modification of our title as well. As a limitation of our study duration of symptoms prior the onset of therapy could have had certain effect on maximal CRP, but this data was not available for analysis. Added in Discussion part paragraph three.

5. Are there any data available on the genetic characteristics of the S. aureus strains - at a minimum their antibiograms - as characteristics of the bacteria may have been a confounder in the maximum CRP level during the first week of therapy.

Answer to question 5.) The procedures named above in answer 4. and the possible effect of S. aureus strains on maximal CRP levels have been discussed in a new paragraph three in the Discussion part on page 8.

6. Lines 42-45. These sentences are not clear. Was BMI independently associated with maximal CRP in the same multivariate model as the rs3091244 A-minor allele carriership? Table 4 shows that they were apparently in the same model. If so, was their interaction a critical factor in the maximal CRP level - either alone or in the multivariate model? 
Answer to question 6) When results were re-evaluated Association of BMI or age to maximal CRP appeared not to be significant in the univariate or multivariate analysis, when the limit of statistical significance used was reset to $\mathrm{p}<0.05$.

Due to invaluable comments critical interactions between one explanatory variable: history of intravenous drug abuse (IDU) with both BMI and age were detected and no independent effect of IDU and age to maximal CRP level really existed. In univariate analysis detected association of IDU to maximal CRP level was also due to critical interaction with existing deep infection focus and if IDU was added to multivariate analysis with significant explanatory variables it resulted in instability of the statistical model and no clear benefit was achieved.

Due to substantial collinearity with IDU (IDUs were younger and also their BMI was much lower compared to other patients) age and BMI were omitted from the multivariate analysis. And finally determinants for the maximal CRP appeared to be presence of deep infection focus and the A- minor allele of rs30912449.

The unclear sentences have been omitted in the revised version of the manuscript.

7. Table 1. While information about the 145 patients is interesting, it would be more relevant to compare the indicated variables for these 145 patients with the larger group of 430 patients from the original study. This would address the question: How representative of patients generally presenting with SAB were the 145 patients included in this manuscript?

Answer to question 7) The demographic and underlying factors of our subgroup of patients have been compared to the original study population of 430 patients in the Discussion part paragraph three of the manuscript (Page 8). No significant differences between our patient population and the original patient material were found. Unfortunately, due to ethical regulations related to gene sampling all patients in the original data set could not be included into the present analysis. We found the comparison of the two patient populations confounding for the reader in a tabular form. After all, only data from the subgroup of patients is presented in the present manuscript.

\section{Reviewer \#2}

Reviewer \#2: The science in the paper is solid. The finding that CRP levels reflect the patients genetic background is important information. The paper was well-written, I could only find one typographical error (p3, line 12, remove camma after "Although, ". I would recommend publishing it as it stands.

Answer: The typographical error has been corrected on Page 3, line 5.

We hope that you would find our revised manuscript suitable to be published in European Journal of Clinical Microbiology \& Infectious Diseases.

Yours sincerely

Tomi Mölkänen, MD 
Division of Infectious Diseases

Department of Medicine

Helsinki University Central Hospital

P.O. Box 348

00029 HUS Helsinki

FINLAND

Tel. +358-50-427 2153

Fax +358-9-471 75900

E-mail: tomi.j.molkanen@hus.fi 


\section{Genetic polymorphism of C-reactive protein (CRP) gene and a deep infection focus determine maximal serum CRP level in Staphylococcus aureus bacteremia}

Tomi Mölkänen, Annina Rostila, Eeva Ruotsalainen, Mervi Alanne, Markus Perola and Asko Järvinen

The affiliations and addresses of the authors:

Tomi Mölkänen, Eeva Ruotsalainen, Asko Järvinen:

Division of Infectious Diseases, Department of Medicine, Helsinki University Central Hospital, Helsinki, Finland

Annina Rostila, Mervi Alanne and Markus Perola

Department of Chronic Disease Prevention, Unit of Public Health Genomics, National Institute for Health and Welfare, Helsinki, Finland

The first two authors contributed equally to this work

Keywords: Staphylococcus aureus bacteremia, C-reactive protein, single nucleotide polymorphisms

Corresponding author:

Tomi Mölkänen, MD

Division of Infectious Diseases

Department of Medicine

Helsinki University Central Hospital

P.O. Box 348

00029 HUS Helsinki

FINLAND

Tel. +358-50-427 2153

Fax +358-9-471 75900

E-mail: tomi.j.molkanen@hus.fi 
C-reactive protein (CRP) is widely used in early detection of sepsis or organ dysfunction. Several single nucleotide polymorphisms (SNPs) in the CRP gene are shown to be associated with variability of basal CRP. To clarify the effect of these SNPs to CRP response in systemic infections, we compared genetic and clinical data on patients with Staphylococcus aureus bacteremia (SAB). Six SNPs in the CRP gene region (rs2794521, rs30912449, rs1800947, rs1130864, rs1205 and rs3093075) were genotyped in 145 patients and analyzed for associations with CRP and various clinical outcomes. We found that the rare minor A-allele of triallelic SNP rs30912449 $(\mathrm{C}>\mathrm{T}>\mathrm{A})$ and presence of a deep infection focus were strongly associated to the higher maximal CRP during the first week of SAB. Median of the maximal CRP in patients who had the A-minor allele was $282 \mathrm{mg} / \mathrm{L}$ (interquartile range [IQR, defined as the difference between the third quartile and the first quartile], $169 \mathrm{mg} / \mathrm{L}$ ) but only $179 \mathrm{mg} / \mathrm{L}$ (IQR, $148 \mathrm{mg} / \mathrm{L}$ ) in patients without this allele $(P=0.004)$ and $\mathrm{CRP}$ in patients who had deep infection focus was higher $208 \mathrm{mg} / \mathrm{L}$ (IQR, $147 \mathrm{mg} / \mathrm{L})$ than in other patients $114 \mathrm{mg} / \mathrm{L}(\mathrm{IQR}, 121 \mathrm{mg} / \mathrm{l})(P<0.0001)$. Mortality, degree of leucocytosis, time to defervescence or number of deep infections were not affected by CRP gene SNPs. The maximal CRP during the first week in SAB was partly determined by variation in the CRP gene and partly by presence of deep infection focus. This finding suggests cautiousness in interpreting exceptionally high CRPs from SAB patients and comparison between patients.
\end{abstract}




\section{Introduction}

C-reactive protein (CRP) is rapidly synthesized in liver as a part of acute phase response following infection, injury or trauma [1]. In clinical practice, rising CRP has been found useful in detection of sepsis or organ dysfunction [2]. Changes in CRP levels have been used to monitor the treatment response, whereas the decline of CRP level is one of the earliest markers of improved condition [3]. Although CRP seems to be a good marker of systemic inflammation and a valuable clinical tool in severe infections [4], its exact role in defence against microbes remains incompletely understood [5].

Based on family and twin studies, it is estimated that genetic factors account for $35 \%$ to $40 \%$ of the variance of the changes in basal CRP levels [6-8]. The CRP gene is located on chromosome 1q32 and it consists of 2 exons and 1 intron $[9,10]$. Several SNPs in the CRP gene are shown to be associated with basal CRP level variability [11]. Moreover, in the Women's Genome Health Study seven genetic loci were shown to be associated with circulating CRP levels in a genome-wide setting, including the CRP locus and six other loci with a trans-effect [12]. Some SNPs in the CRP gene might also be associated with an increased risk for ischemic stroke [13], for reduced arterial compliance [14], or even for risk of getting type 2 diabetes mellitus [15]. However, the causative effect of the cis-acting SNPs on ischemic heart disease remains under some controversy [16]. CRP gene SNPs have been related to susceptibility or worse outcome in some infections as well as other diseases. A CRP gene poly (GT) allele was associated with susceptibility to invasive pneumococcal disease [17] and CRP gene promoter region polymorphism rs2794521 with an increased mortality to invasive pneumococcal disease [18]. However, little is known about how the polymorphism affects CRP levels stimulated by infection or trauma. Recently, lower CRP levels after coronary by-pass operation have been shown to be associated to minor allele of the synonymous coding SNP rs1800947 within exon 2 in the CRP gene [19]. This data indicates that polymorphisms in the CRP gene might be an important factor in CRP response in severe systemic infections. However, the effect of these variations on CRP levels in severe infections has not been evaluated.

S. aureus is the second most common bloodstream isolate in all age groups and it still carries high overall mortality up to $39 \%$ [20-22]. In practice, the clinical course of S. aureus bacteremia (SAB) is determined by its complications, particularly by the development of deep infections and thromboembolic events [23-25]. The reported frequency of deep infection foci in SAB varies greatly, but in recent trial it was over 80\% [26]. Therefore, SAB could be a suitable infection to study the possible effect of genetic polymorphisms to frequency 
of complications and CRP response. To assess the possible contribution of variations in the CRP gene to complications in SAB we genotyped six SNPs in the CRP gene and analyzed their possible correlation to CRP levels and to various clinical outcome parameters.

\section{Methods}

Patient population

A total of 430 patients with blood culture positive for $S$. aureus were enrolled consecutively in 5 university hospitals and in 7 tertiary care hospitals in Finland between January and May 1999, and between January 2000 and August 2002. The trial aimed primarily to examine the potential of two fluoroquinolones (trovafloxacin and levofloxacin) to reduce the high mortality and complication rates in SAB, when added to the standard treatment [26]. The exclusion criteria were: age younger than 18 years, imprisonment, proven or suspected pregnancy, breastfeeding, epilepsy, another bacteremia during the previous 28 days, polymicrobial bacteremia $(\geq 3$ microbes), history of allergy to any quinolone antibiotic, previous tendinitis during a fluoroquinolone therapy, prior fluoroquinolone use for more than 5 days before randomization, positive culture for S. aureus only from a central intravenous catheter, meningitis, neutropenia $\left(<0.5 \times 10^{9}\right.$ cells/L) or failure to supply an informed consent. Patients with bacteremia due to methicillin-resistant $S$. aureus (MRSA) and a $S$. aureus strain resistant to any fluoroquinolone were also excluded [26]. Each patient was recruited into the study only once to avoid double inclusion in repeated bacteremia. The protocol was approved by the ethics committees of all study sites. Written informed consent was obtained from all patients or their representatives. Permission for genetic blood samples was asked for patients only from Helsinki University Central Hospital. Thus, the genetic blood samples were obtained from 151 of 158 patients from this study site. Blood samples from 3 patients could not be obtained for further analysis and 3 subjects were discarded due to technical problems with insufficient DNA yield. In total, 145 patients were included for this study from Helsinki University Central Hospital. 
Definitions

Intravenous drug users (IDUs) were defined as patients who had injected drugs within the past 6 months before randomization based on a history taken on admission. SAB was hospital-acquired if the first positive blood culture was obtained $\geq 48$ hours after admission or the patient was a resident in a long-term care facility or had attended haemodialysis within the preceding 2 months. Prognosis or severity of underlying diseases were characterized as healthy, nonfatal, ultimately or rapidly fatal disease according to the criteria of McCabe and Jackson [27]. Infection focus was documented by clinical, bacteriological, radiological, or pathological investigations. Intravenous catheter-associated bacteremia was defined using the guidelines of the Infectious Disease Society of America [28]. Deep infection focus was classified as endocarditis, pneumonia, deep-seated abscess, osteomyelitis, septic arthritis, meningitis, septic thrombophlebitis, mediastinitis, urinary tract infection, infection of a prosthetic device, or recurrent SAB as described in our previously published article [29]. Time to defervescence was recorded in days until axillary temperature was $<37.5^{\circ} \mathrm{C}$.

Serum CRP and leukocyte measurements

Blood samples for CRP measurement and leukocyte count were conducted on the day of positive blood culture for $S$. aureus, at randomization and every other day during the first week. Serum concentrations of CRP and leukocyte count were measured in the study site laboratory by standard laboratory methods. The serum or plasma (use of plasma instead of serum begun 18.3.2002) was subjected to automatic immunoturbidimetric analysis using analyzers 917 or Modular PP-analyzer (Hitachi Ltd, Tokyo, Japan) and Tina-quant CRP reagents (Roche Diagnostics, Tina-quant CRP). The normal value of CRP concentration was <10 mg/L for both methods. Leukocytosis was determined if white blood cell count was over $12 \times 10^{9}$ cells/L.

DNA sequencing and genotyping

DNA was extracted using phenol chloroform extraction method. DNA quantity was measured by absorbance at $260 \mathrm{~nm}$ and by Pico Green fluorescence assay (PicoGreen dsDNA Quantitation Kit, Molecular Probes, Carlsbad, USA). The detection of SNPs was performed by the analysis of primer extension products from amplified genomic DNA using Sequenom MassArray system with the homogeneous Mass Extension (hME) 
reaction (Sequenom, San Diego, USA). PCR and extension reactions were designed using MassARRAY design rs3091244, rs1800947, rs1130864, rs1205 and rs3093075) were genotyped in all samples. SNPs were selected as haplotype bin tagging SNPs covering the entire gene as well as large parts of the untranslated regions of the $5^{\prime}$ and $3^{\prime}$ ends of the gene.

Statistics

Statistical analyses were performed using SPSS® version 14.0. (SPSS Inc., Chicago, IL, USA). Within each SNP locus genotypic frequencies were tested against values expected from Hardy-Weinberg proportion. The associations between categorical variables were analyzed by $\mathrm{X}^{2}$-test or Fisher's exact test when appropriate. Preliminary analysis of normality was performed for continuous variables using the Kolmogorov-Smirnov and Shapiro-Wilk tests. For skewed variables heterogeneity of genotype groups was tested with Kruskal-Wallis H test. Linear regression univariate analyses were first performed to analyze association between each explanatory variable and outcome variable. Clinically meaningful explanatory variables showing association in univariate analysis $(P<0.05)$ with the outcome were then included in the multivariate regression in order of strength of their correlation with the outcome variable. When a new explanatory variable was shown to contribute to the variance, influence on the variables already in the model and possible collinearity with them was assessed. All tests were 2-tailed and $(P<0.05)$ were considered significant. For the multiple comparisons, the FDR estimation method was applied to association analyses.

\section{Results}

In total, 145 patients with SAB were included into this study. Majority of the patients were male (66\%) and their mean age was 52 years (Table 1). A deep infection focus was found in 124 (86\%) patients within the 3 months study period.

The genotype distributions of CRP gene SNPs did not deviate from the Hardy-Weinberg equilibrium (Online Resource). Among the six selected haplotype bin tagging SNPs, two are located in the promoter region rs2794521 and rs3091244, one is located in exon 2 rs1800947, one in 3'UTR region rs 1130864, and two in 3' 
flanking region rs1205 and rs3093075. All these SNPs were found to be in strong linkage disequilibrium (LD) by Haploview 3.2 program [30]. In particular, rs3091244 A-minor allele is in full LD with rs3093075 and rs3091244 T-minor allele with rs1130864. All CRP gene SNPs except rs1205 are within one haplotype block.

When SNPs of the CRP gene were analyzed in additive and recessive genetic models they were found not to affect the CRP levels at the time of $S$. aureus positive blood culture or 7 days after it. However, the maximal CRP levels during the first week of illness were significantly elevated in patients who had either A-minor allele of rs3091244 or T-minor allele of rs3093075 when compared to patients without minor alleles of these SNPs (Table 2). Due to strong LD between these two SNPs, the results reflect the same signal.

No differences were observed in occurrence of predisposing factors, underlying diseases and clinical manifestations or number of patients with a deep infection focus in patients with one copy of minor allele A of rs3091244 when compared to patients without this minor allele (Table 3). Presence of a deep infection focus and rs3091244 A- minor allele carriage were both found to be significantly associated to maximal CRP level during the first week and this effect persisted in multivariate analysis (Table 4). Associations were retained even after the multiple comparisons with FDR estimation using an FDR threshold <0.10 (Table 4). The median of the maximal CRP level in patients who had a deep infection focus was $208 \mathrm{mg} / \mathrm{L}$ (IQR, 147mg/L) but only 114 $\mathrm{mg} / \mathrm{L}(\mathrm{IQR}, 121 \mathrm{mg} / \mathrm{l})$ in patients without it $(P<0.0001)$. Other possible explaining factors like age, sex, BMI, surgical intervention or intravenous drug abuse were not found to be significant determinants of the maximal CRP level (Table 4).

Associations between any other parameter and SNPs were not detected when data was analyzed in additive and recessive models. The degree of leukocytosis, time to defervescence, number of any deep infection foci during the first week or three months, the number of patients who had intravenous-catheter-associated bacteremia, or who died within 28 days or three months were not influenced by polymorphisms. 


\section{Discussion}

To our knowledge, this is the first study to investigate the association between CRP gene SNPs and CRP levels in acute phase of SAB. Polymorphisms in the CRP locus are shown to have strong influence on low basal CRP levels [11] but reports on the effect of these SNPs on high CRP values during systemic infections are few. We assessed the genotypes of six SNPs in the CRP gene in 145 clinically evaluated SAB patients. We demonstrated that SNP rs3091244 in the promoter region of the CRP gene was clearly associated with higher maximal CRP elevation during the first week of illness. This gene region is important in the transcriptional activity of the CRP gene [32]. Patients who were rare minor A-allele carriers of SNP rs3091244 had significantly higher maximal CRP levels as compared to patients who were not. This genetic variant, however, did not have an effect on initial CRP level measured on the day of $S$. aureus positive blood culture or the subsequent decline of CRP level during the treatment. Neither did it affect the outcome of the disease as measured by mortality, number of deep infections or time to defervescence.

We observed significantly higher maximal CRP levels among the patients who had deep infection focus during the first week of $\mathrm{SAB}$ as compared to those who did not. We were not able to find this result in previous literature. However, the importance of deep infection foci on the prognosis has been shown [23-25]. Surgical procedures or even placement of a central venous catheter (CVI) might increase CRP levels but this was not observed in our study population. In univariate analysis surgical interventions were not associated to elevated CRP levels and only one of the patients had CVIs placed during the first week.

Our study population was a subgroup of patients in a larger study on $S$. aureus bacteremia which might have an effect on the results. However, the demographic factors and underlying diseases did not differ between our patient group and the original larger patient population [26]. Inadequate antibiotic treatment during the first week has not affected the results as all patients received microbiologically verified effective treatment already from the blood culture day [26]. As a limitation of the study data on duration of symptoms prior the onset of therapy is not available and was not analysed. Infections due to various S. aureus bacterial strains might have different effects on the CRP production although no data on this exists. The effect of variations in $S$. aureus strains in our results seems, however, not likely as the strains were highly variable [33]. 
In contrast to our results, SNP rs2794521 in the promoter region of the CRP gene has been reported to be that this SNP would have an impact on outcome or CRP levels in SAB. Whether this relation to mortality counts only for S. pneumoniae or is due to other confounding factors remains to be elucidated. It has to be notified that no relationship of polymorphisms in the CRP gene and mortality was observed in the same study in bacteremia due to other microbes, namely $\alpha$-hemolytic streptococci or Escherichia coli [18]. The minor allele of SNP rs1800947 in the CRP gene was recently shown to be associated to significantly lower CRP levels in patients recovering from coronary by-pass surgery [19]. In our study, this same genotype did not seem to have any effect on CRP levels but the relatively small patient population might not make it possible to observe such an effect in our study. Other studies on CRP gene polymorphism in severe acute infections are not available.

Interestingly, this same triallelic SNP rs3091244, which we found to be associated with maximal CRP levels in SAB has been related to high basal CRP levels as well [32, 34-36]. Although reduction of CRP levels has been shown to be clinically beneficial and is associated with positive cardiovascular outcomes [37], associations of polymorphisms in CRP gene with development of chronic diseases like type 2 diabetes [15, 38] or ischemic heart disease remain under some controversory.

In our study, previously reported associations of CRP gene SNPs on the unexpectedly low levels of CRP could not be seen which might be due to rather small sample size in our study. However, this might also be due to healing of infection having a greater impact on the decline of CRP as compared to genetic variability. This further suggests that in studies concerning impact of CRP gene SNPs on basal CRP level, individuals with any infections should be carefully excluded from the patient population.

To answer the question whether our finding is specific for a CRP response in SAB requires further investigation. However, already at this time one can draw certain conclusions. Our study can help to understand why individuals have so different maximal responses in CRP levels under seemingly similar conditions in bacteremia and why exceptionally high CRP does not necessarily predict the clinical course of SAB. Polymorphisms were not associated with CRP levels in the beginning of SAB. These levels have more variable factors than maximal CRP. CRP measurements started when positive blood culture was achieved and period of time from the onset of symptoms and first blood sampling varied between patients. This may have influenced our results. 
Polymorphisms did not seem to have an effect on the decline of CRP levels and this encourages continued use

of CRP measurement as a clinical tool in individual surveillance of recovery.

In conclusion, our study reminds to interpret exceptionally high CRP values with caution and to avoid comparing them between patients. The results of this study suggest that disease severity as assessed by occurrence of a deep infection focus and genetic variability in CRP gene might be the factors that determine the maximal CRP level in SAB. The same polymorphism that was associated with high basal CRP levels was found to be related to significantly higher maximal CRP concentrations in SAB. 


\section{References}

1. Black S, Kushner I, Samols D. C-reactive protein. J Biol Chem 2004;279(47):48487-90.

2. Povoa P. C-reactive protein: A valuable marker of sepsis. Intensive Care Med 2002;28(3):235-43.

3. Povoa P, Coelho L, Almeida E, et al. Early identification of intensive care unit-acquired infections with daily monitoring of C-reactive protein: A prospective observational study. Crit Care 2006;10(2):R63.

4. Lobo SM, Lobo FR, Bota DP, et al. C-reactive protein levels correlate with mortality and organ failure in critically ill patients. Chest 2003;123(6):2043-9.

5. Agrawal A, Suresh MV, Singh SK, Ferguson DA,Jr. The protective function of human C-reactive protein in mouse models of streptococcus pneumoniae infection. Endocr Metab Immune Disord Drug Targets 2008;8(4):231-7.

6. Pankow JS, Folsom AR, Cushman M, et al. Familial and genetic determinants of systemic markers of inflammation: The NHLBI family heart study. Atherosclerosis 2001;154(3):681-9.

7. Retterstol L, Eikvar L, Berg K. A twin study of C-reactive protein compared to other risk factors for coronary heart disease. Atherosclerosis 2003;169(2):279-82.

8. MacGregor AJ, Gallimore JR, Spector TD, Pepys MB. Genetic effects on baseline values of C-reactive protein and serum amyloid a protein: A comparison of monozygotic and dizygotic twins. Clin Chem 2004;50(1):130-4.

9. Woo P, Korenberg JR, Whitehead AS. Characterization of genomic and complementary DNA sequence of human C-reactive protein, and comparison with the complementary DNA sequence of serum amyloid P component. J Biol Chem 1985;260(24):13384-8.

10. Walsh MT, Divane A, Whitehead AS. Fine mapping of the human pentraxin gene region on chromosome 1q23. Immunogenetics 1996;44(1):62-9.

11. Hage FG, Szalai AJ. C-reactive protein gene polymorphisms, C-reactive protein blood levels, and cardiovascular disease risk. J Am Coll Cardiol 2007;50(12):1115-22.

12. Ridker PM, Pare G, Parker A, et al. Loci related to metabolic-syndrome pathways including LEPR,HNF1A, IL6R, and GCKR associate with plasma C-reactive protein: The women's genome health study. Am J Hum Genet 2008;82(5):1185-92.

13. Morita A, Nakayama T, Soma M. Association study between C-reactive protein genes and ischemic stroke in japanese subjects. Am J Hypertens 2006;19(6):593-600. 
14. Eklund C, Kivimaki M, Islam MS, et al. C-reactive protein genetics is associated with carotid artery

15. Zee RY, Germer S, Thomas A, et al. C-reactive protein gene variation and type 2 diabetes mellitus: A casecontrol study. Atherosclerosis 2008;197(2):931-6.

16. Zacho J, Tybjaerg-Hansen A, Jensen JS, Grande P, Sillesen H, Nordestgaard BG. Genetically elevated Creactive protein and ischemic vascular disease. N Engl J Med 2008;359(18):1897-908.

17. Roy S, Hill AV, Knox K, Griffiths D, Crook D. Research pointers: Association of common genetic variant with susceptibility to invasive pneumococcal disease. BMJ 2002;324(7350):1369.

18. Eklund C, Huttunen R, Syrjanen J, Laine J, Vuento R, Hurme M. Polymorphism of the C-reactive protein gene is associated with mortality in bacteraemia. Scand J Infect Dis 2006;38(11-12):1069-73.

19. Perry TE, Muehlschlegel JD, Liu KY, et al. C-reactive protein gene variants are associated with postoperative C-reactive protein levels after coronary artery bypass surgery. BMC Med Genet 2009;10(1):38.

20. Conterno LO, Wey SB, Castelo A. Risk factors for mortality in staphylococcus aureus bacteremia. Infect Control Hosp Epidemiol 1998;19(1):32-7.

21. Soriano A, Martinez JA, Mensa J, et al. Pathogenic significance of methicillin resistance for patients with staphylococcus aureus bacteremia. Clin Infect Dis 2000; 30(2):368-73.

22. Benfield T, Espersen F, Frimodt-Moller N, et al. Increasing incidence but decreasing in-hospital mortality of adult staphylococcus aureus bacteraemia between 1981 and 2000. Clin Microbiol Infect 2007; 13(3):257-63.

23. Mylotte JM, Tayara A. Staphylococcus aureus bacteremia: Predictors of 30-day mortality in a large cohort. Clin Infect Dis 2000; 31(5):1170-4.

24. Fowler VG,Jr, Olsen MK, Corey GR, et al. Clinical identifiers of complicated staphylococcus aureus bacteremia. Arch Intern Med 2003;163(17):2066-72.

25. Fatkenheuer G, Preuss M, Salzberger B, et al. Long-term outcome and quality of care of patients with staphylococcus aureus bacteremia. Eur J Clin Microbiol Infect Dis 2004; 23(3):157-62.

26. Ruotsalainen E, Jarvinen A, Koivula I, et al. Levofloxacin does not decrease mortality in staphylococcus aureus bacteraemia when added to the standard treatment: A prospective and randomized clinical trial of 381 patients. J Intern Med 2006;259(2):179-90.

27. Jackson GG, Arana-Sialer JA, Andersen BR, Grieble HG, McCabe WR. Profiles of pyelonephritis. Arch Intern Med 1962;110:63-75. 
28. Mermel LA, Farr BM, Sherertz RJ, et al. Guidelines for the management of intravascular catheter-related

29. Ruotsalainen E, Sammalkorpi K, Laine J, et al. Clinical manifestations and outcome in staphylococcus aureus endocarditis among injection drug users and nonaddicts: A prospective study of 74 patients. BMC Infect Dis 2006; 6:137.

30. Benjamini Y, Hochberg Y. Controlling the false discovery rate: A practical and powerful approach to multiple testing. Journal of the Royal Statistical Society. Series B (Methodological) 1995; 57(1):289-300.

31. Barrett JC, Fry B, Maller J, Daly MJ. Haploview: Analysis and visualization of LD and haplotype maps. Bioinformatics 2005; 21(2):263-5.

32. Szalai AJ, Wu J, Lange EM, et al. Single-nucleotide polymorphisms in the C-reactive protein (CRP) gene promoter that affect transcription factor binding, alter transcriptional activity, and associate with differences in baseline serum CRP level. J Mol Med 2005; 83(6):440-7.

33. Ruotsalainen E, Karden-Lilja M, Kuusela P, et al. Methicillin-sensitive staphylococcus aureus bacteraemia and endocarditis among injection drug users and nonaddicts: Host factors, microbiological and serological characteristics. J Infect 2008; 56(4):249-56.

34. Kovacs A, Green F, Hansson LO, et al. A novel common single nucleotide polymorphism in the promoter region of the C-reactive protein gene associated with the plasma concentration of C-reactive protein. Atherosclerosis 2005; 178(1):193-8.

35. Kathiresan S, Larson MG, Vasan RS, et al. Contribution of clinical correlates and 13 C-reactive protein gene polymorphisms to interindividual variability in serum C-reactive protein level.

Circulation 2006;113(11):1415-23.

36. Suk Danik J, Chasman DI, Cannon CP, et al. Influence of genetic variation in the C-reactive protein gene on the inflammatory response during and after acute coronary ischemia. Ann Hum Genet 2006; 70(Pt 6):705-16.

37. Ridker PM. Clinical application of C-reactive protein for cardiovascular disease detection and prevention. Circulation 2003; 107(3):363-9.

38. Wolford JK, Gruber JD, Ossowski VM, et al. A C-reactive protein promoter polymorphism is associated with type 2 diabetes mellitus in Pima indians. Mol Genet Metab 2003; 78(2):136 
Table 1 Characteristics and underlying diseases of

\begin{tabular}{|c|c|}
\hline Age (years, mean \pm SD) & $52 \pm 17$ \\
\hline Male sex & $95(66 \%)$ \\
\hline \multicolumn{2}{|l|}{ Predisposing factors } \\
\hline Hospital acquired & $87(60 \%)$ \\
\hline Prosthetic or intravascular device & $68(47 \%)$ \\
\hline Previous surgery ${ }^{\mathrm{a}}$ & $36(25 \%)$ \\
\hline Central intravenous catheter & $31(21 \%)$ \\
\hline Intravenous drug abuse $\mathrm{e}^{\mathrm{b}}$ & $27(19 \%)$ \\
\hline Corticosteroid use $\geq 1$ month & $16(11 \%)$ \\
\hline Alcohol abuse & $9(6 \%)$ \\
\hline Immunosuppressive therapy & $14(10 \%)$ \\
\hline \multicolumn{2}{|l|}{ Underlying diseases } \\
\hline Coronary artery disease & $32(22 \%)$ \\
\hline Diabetes & $38(26 \%)$ \\
\hline Chronic lung disease ${ }^{c}$ & $20(14 \%)$ \\
\hline Chronic renal failure & $26(18 \%)$ \\
\hline Hepatic cirrhosis & $4(3 \%)$ \\
\hline Autoimmune disease & $9(6 \%)$ \\
\hline Malignancy & $23(16 \%)$ \\
\hline HIV & $6(4 \%)$ \\
\hline \multicolumn{2}{|l|}{ McCabe`s classification ${ }^{\mathrm{d}}$} \\
\hline Healthy or nonfatal & $99(68 \%)$ \\
\hline Ultimately or rapidly fatal & $46(32 \%)$ \\
\hline
\end{tabular}

NOTE. Data are no. (\%) of patients, unless otherwise indicated.

a During 3 months or

$\mathrm{b}_{\text {during }} 6$ months preceding the positive blood culture.

${ }^{\mathrm{c}}$ Chronic obstructive pulmonary disease, bronchial asthma and other pulmonary disease.

$\mathrm{d}_{\text {Patients were grouped modifying original classification [27] }}$ 
Table 2 Distribution of SNP rs3091244 genotypes in 116 patients and median CRP levels (mg/L) and interquartile range (IQR) on the first week of Staphylococcus aureus bacteremia

\begin{tabular}{|c|c|c|c|c|c|c|c|c|}
\hline & Genotype & & $\mathrm{CRP}^{\mathrm{b}}$ & & $\mathrm{CRP}^{\mathrm{ce}}$ & & $\mathrm{CRP}^{\mathrm{d}}$ & \\
\hline $\mathrm{SNP}^{\mathrm{a}}$ & distribution & $n$ & Day 0 & $P$-value & Day 7 & $\mathrm{P}$ & Max & $P$-value \\
\hline \multirow[t]{10}{*}{ rs3091244 } & Additive & & & & & & & \\
\hline & TT & 21 & $158(206)$ & & $20(74)$ & & $182(167)$ & \\
\hline & $\mathrm{TC}$ & 55 & $171(166)$ & & $44(84)^{\mathrm{e}}$ & & 193 (157) & \\
\hline & TA & 4 & $222(364)$ & 0.550 & $54(124)$ & 0.594 & $299(202)$ & 0.023 \\
\hline & $\mathrm{CC}$ & 28 & $157(109)^{e}$ & & $33(65)$ & & $163(102)$ & \\
\hline & $\mathrm{CA}$ & 8 & $224(186)$ & & $54(62)$ & & $280(188)$ & \\
\hline & A-minor & & & & & & & \\
\hline & & & & & & & & \\
\hline & $\mathrm{TT}+\mathrm{TC}+\mathrm{CC}$ & 104 & $166(160)^{\mathrm{e}}$ & & $42(70)^{\mathrm{e}}$ & & 179 (148) & \\
\hline & $\mathrm{TA}+\mathrm{CA}$ & 12 & $224(186)$ & 0.111 & $47(64)$ & 0.773 & 282 (169) & $0.004 *$ \\
\hline
\end{tabular}

CRP values within each additive or recessive model were analysed by Kruskal Wallis $\mathrm{H}$ test.

a National Center for Biotechnology Information SNP database accession number.

${ }^{\text {b }}$ Median CRP (mg/L) and (IQR) when positive blood culture for S.aureus was achieved.

${ }^{c}$ Median CRP (mg/L) and (IQR) at the end of the first week of SAB.

$\mathrm{d}$ Highest median CRP (mg/L) and (IQR) of the first week of SAB .

${ }^{\mathrm{e}}$ One CRP level measurement is missing from value of median.

* Multiple $P$-value testing FDR $<0.10$ 
Table 3 Distribution of characteristics and underlying diseases in 116 Staphylococcus aureus bacteremia patients stratified by the minor allele A of rs3091244. Data is given as number (\%) of patients, unless otherwise indicated. OR denotes odds ratio for minor allele A-carriers.

\begin{tabular}{|c|c|c|c|c|c|}
\hline Characteristics & $\begin{array}{l}\text { TA+CA } \\
n=12\end{array}$ & $\begin{array}{l}\text { TT+TC+CC } \\
n=104\end{array}$ & $\begin{array}{l}\text { Total } \\
n=116\end{array}$ & OR $(95 \% \mathrm{CI})$ & $P$ \\
\hline Age (years, mean \pm SD) & $55 \pm 22$ & $53 \pm 17$ & $53 \pm 18$ & - & 0.71 \\
\hline Male sex & $8(67)$ & $69(66)$ & $77(66)$ & $1.0(0.3-3.6)$ & 1.00 \\
\hline \multicolumn{6}{|l|}{ Predisposing factors } \\
\hline Hospital acquired & $8(67)$ & $62(60)$ & $70(60)$ & $1.4(0.4-4.8)$ & 0.76 \\
\hline Prosthetic or intravascular device & $6(50)$ & $50(48)$ & $56(48)$ & $1.1(0.3-3.6)$ & 1.00 \\
\hline Previous surgery ${ }^{a}$ & $3(25)$ & $25(24)$ & $28(24)$ & $1.1(0.3-4.2)$ & 1.00 \\
\hline Central intravenous catheter & $1(8)$ & $21(20)$ & $22(19)$ & $0.4(0.0-2.9)$ & 0.46 \\
\hline Intravenous drug abuse ${ }^{b}$ & $3(25)$ & $19(18)$ & $22(19)$ & $1.5(0.4-6.0)$ & 0.70 \\
\hline Corticosteroid use $\geq 1$ month & $2(17)$ & $9(9)$ & $11(10)$ & $2.1(0.4-11.2)$ & 0.32 \\
\hline Alcohol abuse & $0(0)$ & $8(8)$ & $8(7)$ & - & 1.00 \\
\hline Immunosupressive therapy $b$ & $1(8)$ & $9(9)$ & $10(9)$ & $1.0(0.1-8.3)$ & 1.00 \\
\hline \multicolumn{6}{|l|}{ Underlying diseases } \\
\hline Coronary artery disease & $4(33)$ & $24(23)$ & $28(24)$ & $1.7(0.5-6.0)$ & 0.48 \\
\hline Diabetes & $3(25)$ & $26(25)$ & $29(25)$ & $1.0(0.3-4.0)$ & 1.00 \\
\hline Chronic lung disease $^{\mathrm{c}}$ & $2(17)$ & $15(14)$ & $17(15)$ & $1.2(0.2-6.0)$ & 0.69 \\
\hline Chronic renal failure & $1(8)$ & $16(15)$ & $17(15)$ & $0.5(0.1-4.2)$ & 1.00 \\
\hline Hepatic cirrhosis & $0(0)$ & $4(4)$ & $4(3)$ & - & 1.00 \\
\hline Autoimmune disease & $1(8)$ & $5(5)$ & $6(5)$ & $1.8(0.2-16.8)$ & 0.49 \\
\hline Malignancy & $2(17)$ & $15(14)$ & $17(15)$ & $1.2(0.2-6.0)$ & 0.69 \\
\hline HIV & $0(0)$ & $6(6)$ & $6(5)$ & - & 1.00 \\
\hline Deep infection focus & $11(92)$ & $82(79)$ & $93(80)$ & $3.0(0.4-24)$ & 0.46 \\
\hline \multicolumn{6}{|l|}{ McCabe`s classification $d$} \\
\hline Healthy or nonfatal & $8(67)$ & $75(72)$ & $83(72)$ & $0.7(0.2-2.8)$ & 0.74 \\
\hline Ultimately or rapidly fatal & $4(33)$ & $29(28)$ & $33(28)$ & $1.3(0.4-4.6)$ & 0.74 \\
\hline
\end{tabular}

NOTE. Genotyping of SNP rs3091244 was successful only in 116 patients.

a During 3 months or ${ }^{b}$ during 6 months preceding the positive blood culture.

${ }^{\mathrm{c}}$ Chronic obstructive pulmonary disease, bronchial asthma and other pulmonary disease.

$\mathrm{d}$ Patients were grouped modifying original classification [27]. 
Table 4 Univariates and adjusted multiple regression analysis on variables affecting the maximal CRP levels on the first week of Staphylococcus aureus bacteremia

\begin{tabular}{|c|c|c|c|c|c|c|c|c|}
\hline \multirow{3}{*}{$\begin{array}{l}\text { Variable } \\
\text { Age }\end{array}$} & \multicolumn{3}{|c|}{ Univariate } & \multirow{3}{*}{$\begin{array}{r}P \text {-value } \\
0.194\end{array}$} & \multicolumn{3}{|c|}{ Multivariate } & \multirow[t]{2}{*}{$P$-value } \\
\hline & $B$ & & S.E. & & $B$ & & S.E. & \\
\hline & -0.6 & \pm & 0.5 & & - & - & - & - \\
\hline Sex & 7.0 & \pm & 17.7 & 0.696 & - & - & - & - \\
\hline BMI & 2.4 & \pm & 1.5 & 0.097 & - & - & - & - \\
\hline Surgical intervention & 14.4 & \pm & 18.4 & 0.436 & - & - & - & - \\
\hline Deep infection focus & 89.7 & \pm & 19.8 & $<0.0001 *$ & 98.4 & \pm & 28.3 & $<0.0001 *$ \\
\hline Intravenous drug abuse ${ }^{a}$ & 28.5 & \pm & 21.5 & 0.187 & - & - & - & - \\
\hline Carriership of rs3091244 A-minor allele & 102.3 & \pm & 30.5 & 0.001 & 89.7 & \pm & 21.6 & $0.002 *$ \\
\hline
\end{tabular}

a During 6 months preceding the positive blood culture

NOTE. Variables were selected for multivariate analysis if univariate association

was detected at $(P<0.05)$. Unstandardized coefficients $B<0$ indicate an inverse association between the variable and CRP level.

* Multiple $P$-value testing FDR $<0.10$

Adjusted model $R^{2}=0.217$ 
Electronic Supplementary Material
Click here to download Electronic Su

\section{Click here to download Electronic Supplementary Material: Electronic supplementary material[1].doc}




\author{
Alex van Belkum \\ Editor in Chief \\ European Journal of Clinical Microbiology \& Infectious Diseases
}

MS. No. EJCMID-D-10-00008

Please find enclosed our revised manuscript entitled "Genetic polymorphism of C-reactive protein (CRP) gene and a deep infection focus determine maximal serum CRP level in Staphylococcus aureus bacteremia". We are grateful for the valuable comments of the referees which have all lead to changes in manuscript. One of the suggestions of referee 1 led us to reanalyse one part of the statistics which has resulted in a modification of title of our manuscript. We sincerely consider this reanalysis to have improved the manuscript and its importance for the scientific community.

In detail following changes have been made into the manuscript.

Referee \#1.

1) Each patient was included into the study only once. This has been explained in the methods in the paragraph "patient population" on Page 4 lines 20-21.

2) Multiple comparisons has been analysed by False-discovery rate (FDR) estimation. It has been included into the statistics section of methods page 6 lines 19-20. Results from FDR analyses have been shown in tables 2 and 4.

3) Table 2 includes only 116 patients because genotyping in laboratory of SNP rs3091244 was successful only in 116 patients. This specific triallelic SNP turned out to be technically much more challenging to sequence compared to all other biallelic SNPs studied.

4) Surgical procedures during the first week have been analysed as suggested by the referee and were found not to affect the maximal CRP level. However, we analysed also the effect of presence of a deep infection focus on the maximal CRP level and found this association highly significant. Patients with deep infection foci have been added into table 3 and this information into results on Page 7 lines 13-18 and into Table 4. This finding has been further discussed in a new written part of discussion on Page 4, in paragraph two. We considered this finding of so high importance that it has resulted into modification of our title as well.

5) The procedures named above in 4) and the possible effect of $S$. aureus strains on maximal CRP levels have been discussed in a new paragraph three in the Discussion part ort page 8.

6) The unclear sentences have been omitted in the revised version of the manuscript.

7) The demographic and underlying factors of our subgroup of patients have been compared to the original study population of 430 patients in the Discussion part paragraph three of the manuscript (Page 8). No significant differences between our patient population and the original patient material were found. Unfortunately, due to ethical regulations related to gene sampling all patients in the original data set could not be included into the present analysis. We found the comparison of the two patient populations confounding for the reader in a tabular form. After all, only data from the subgroup of patients is presented in the present manuscript. 
Referee \#2

The typographical error has been corrected on Page 3, line 5.

We hope that you would find our revised manuscript suitable to be published in European Journal of Clinical Microbiology \& Infectious Diseases.

Yours sincerely

Tomi Mölkänen, MD

Division of Infectious Diseases

Department of Medicine

Helsinki University Central Hospital

P.O. Box 348

00029 HUS Helsinki

FINLAND

Tel. +358-50-427 2153

Fax +358-9-471 75900

E-mail: tomi.j.molkanen@hus.fi 